\title{
Analysis on the Key Elements of Chinese Characteristic Town
}

\author{
Yali Wang ${ }^{1 *}$ Lu Feng ${ }^{2}$ Yan Liu $^{3}$ \\ 1 School of Economic and Management, Shandong Youth University of Political Science, Jinan, Shandong, 250000, China \\ "Corresponding author.Email: wyljn08125@163.com
}

\begin{abstract}
The construction of characteristic towns is of great significance to the economic transformation and upgrading and the construction of new-type urbanization. On the basis of summarizing previous studies, this study extracts six core elements of the construction of characteristic towns in China, namely, people, industry, environment, culture, innovation and policy. The connotation of the development of featured towns is summarized as follows: people as the core, industry as the lifeblood, environment as the foundation, culture as the guide, innovation as the driving force, and policy as the guarantee".
\end{abstract}

Keywords: characteristic town, people, industry, environment, culture, innovation, policy

\section{INTRODUCTION}

General secretary Xi Jinping attaches great importance to the development of characteristic small towns. When he visited Zhejiang province in May 2015, he fully affirmed the practical experience of characteristic small towns in Zhejiang province. In the same year, he gave important instructions on the work of characteristic towns: the construction of characteristic towns being of great significance to the economic transformation and upgrading 250

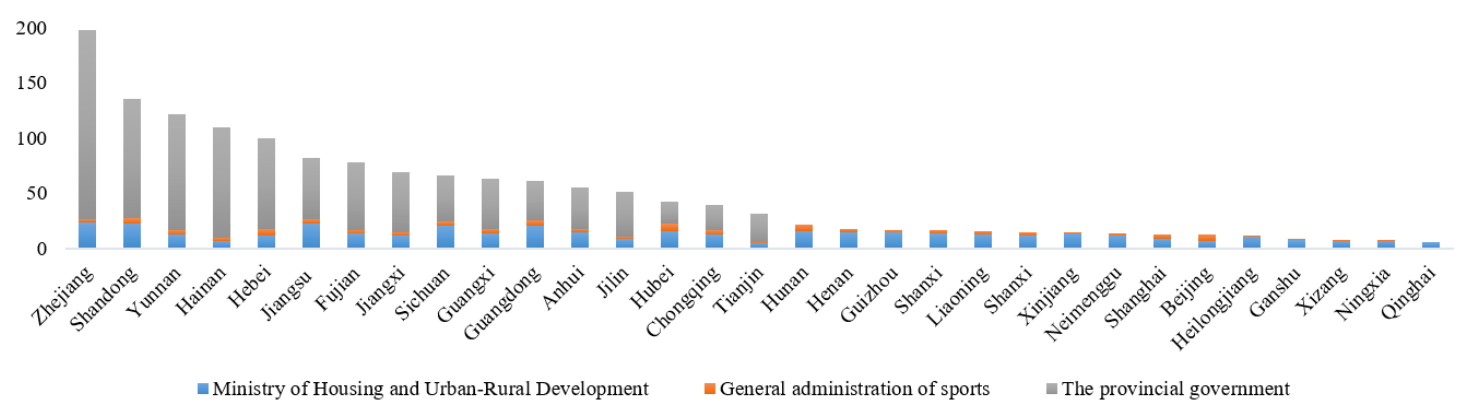

Figure 1 National characteristic town selection survey and the construction of new-type urbanization. Since then, the construction of characteristic towns has started the mode of going to the whole country. At present, the construction of characteristic towns has been carried out in a full swing in more than 20 provinces and cities, playing an increasingly important role in the transformation of economic structure, the promotion of new urbanization, the development of traditional culture, the construction of a beautiful China, the integration of urban and rural development, innovative economic development and other important fields.

\section{LITERATURE REVIEW}

As an independent research topic, "characteristic town" started from the construction of characteristic town in Zhejiang province in 2015. Based on the comprehensive analysis of the existing research results, most of them are discussing the conceptual characteristics, functional orientation, construction and development of featured towns, which is essentially an attempt to answer the question "what is a featured town?" "Why build a special town?" "How do you build the ideal feature town?" waiting for a problem.
In Zhejiang province in 2015, the governor Li Qiang stressed that characteristics, not "town" in the history of administrative division unit, it is also different from industrial park, the scenic spot "zone", but according to the innovation, the coordination, the green development concept, development, sharing, combined with its own characteristics, find industry status, scientific planning, the mining industry characteristics, cultural atmosphere and ecological endowment, formation of "production, city and people," the most important function of organic combination of four integrated platform. Sheng Shihao and Zhang Weiming[1]further defines characteristic town as "characteristic industrial innovation, production, sales and service in one of the emerging industrial spatial 
organization form", think "as a new industrial space organization form, characteristic town is massive economy, the inevitable result of the evolution of industrial cluster development, and regional economy from the inherent requirement of investment-driven to innovation-driven". Ma bin[2] believes that featured town is a brand new urban functional platform with industry as the core and multiple functions organically integrated. Its essential feature is the innovation of urban and industrial development concepts and the reconstruction of development paths, and the promotion of innovation integration through project portfolio, enterprise aggregation and industrial integration. The characteristic town integrates the characteristic industry, the town community, the history culture and the leisure sightseeing and so on many functions as a whole person culture industry type community. Liu Xibin [3] pointed out that distinctive "characteristics" are the primary characteristics of the featured town. "culture is the soul, industry is the root, enterprise is the main body, attracting customers is the key, ecology is the foundation, and atmosphere is open" is the main characteristics of the featured town. Li Qiang believes that the characteristic town is "unique and strong" in industry, "united and united" in function, "fine and beautiful" in form, and "new and lively" in mechanism.

In terms of the functional orientation of featured towns, most of the current studies emphasize that featured towns are the integration of production functions, cultural functions, tourism functions and community functions. $\mathrm{Li}$ Qiang pointed out that the industrial function is the core function of the featured town, and the cultural function is the core of the featured town. The featured town should fully integrate the above four functions in a limited space, so as to form a desirable beautiful scenery, livable environment and entrepreneurial atmosphere while building an industrial ecosystem. Every unique town should have a cultural identity that can leave an unforgettable cultural impression. Yao Shangjian [4] further pointed out that the featured town bears industrial, cultural and social functions and is a space with diversified functions. Although most studies emphasized the integration of functions of featured towns, Wang Xingbin [5] questioned the rationality of the integration of tourism functions and industrial functions. In most cases, he argues, the functions of tourism and industry are more in conflict than convergence. He also further clarified that the root of the difficulty in integrating the two lies in: the core of tourism is consumption, attracting people with "money" to spend as much as possible; the core of industrial development is production, which is to attract as many "talented" people as possible to start businesses and find jobs. The two development paths are completely different. In terms of characteristics of small town construction and development, Cao Shuang and Luo Juan[6]from relying on the resource type town development with Chinese characteristics will be summed up in three types: on the basis of the traditional industry to the resources of the industry agglomeration gathered type town, based on the cultural or natural environment driving environment gathered at the edge of the industry development model town, based on the location advantage and the development of the platform type town. From the perspective of dynamics, Zhang Yinyin and Ding Yuan [7] pointed out that the construction mechanism of a small town can be divided into two categories: the extrinsic type (relying on external forces to build it) and the endogenous type (relying on its own development and growth).From the perspective of the industrial chain, Zhu Yingying [8] summarized that the extension and expansion of the industrial chain, the construction of a pan-industrial chain ecosystem and the formation of a conceptual new space are three special paths for the development of small towns. At the same time, a large number of studies agree that industry, environment, culture, policy, innovation and talent are the core elements of the development of characteristic towns.

\section{SIX ELEMENTS OF CHINESE CHARACTERISTIC TOWN}

Based on practical experience and logical deduction, this paper summarizes the components of characteristic town from six aspects: people, industry, environment, culture, innovation and policy. On the basis of this, it summarizes the basic characteristics of the characteristic town: "people as the core, industry as the lifeblood, environment as the foundation, culture as the guide, innovation as the driving force, and policy as the guarantee".

\subsection{People as the core}

From the point of view of taking people as the core, the construction of characteristic town should take the promotion of people's all-round development as the criterion and goal of action. Characteristic towns should provide "people" with more diversified and higher-quality employment opportunities, and build a comprehensive and multi-level learning system. Feature towns should promote functional integration to foster complete and funny social networks. The integration of functions increases people's contact opportunities, expands social networks, and satisfies people's social needs. The characteristic town also provides the platform and the support for the comprehensive improvement of human quality. The free development of people's personality should be based on diversified work, life and choice opportunities, which also requires the town to have an inclusive, open and humanized cultural atmosphere and a stage for people to show their individuality. Finally, the harmonious coexistence between man and nature is also a necessary requirement for the overall development of man, thus it is necessary for the characteristic town to provide a good ecological environment.

\subsection{Industry as the lifeblood}

Industry is the lifeblood of the existence and development 
of characteristic small towns, mainly embodied in the creation of knowledge, wealth accumulation and employment supply. Real knowledge comes from practice, and industry is a kind of comprehensive practice activity. The specialized and localized knowledge created by industry is of great significance to promote the economic, cultural and ecological development of characteristic towns. Without the development of industry, the urban environment and infrastructure will have no financial guarantee, and the construction of small towns will become a tree without roots. Industrial development is also the source of job creation. Without the employment provided by the industry, the town workers will have no source of income, and the town will not be able to maintain the population and talent.

\subsection{Environment as the foundation}

The environment determines what kind of people and industries the characteristic town can attract, and to a large extent, it also shows the characteristics of the town. The reason why the environment is the foundation of the development of characteristic towns is that whether it is the core people, the lifeblood industry, or the culture, policy and innovation activities, all need to be rooted in the environment. The environment will affect the size and type of human inflow, and a convenient living environment will help reduce the living cost of residents, as well as the clustering of population. Production and ecological environment will affect the development cost of characteristic towns. The improvement of production environment means that the production cost will be reduced and the industrial agglomeration scale will be larger under the equilibrium state. Under the condition of openness, culture will be conceptualized according to the external environment, especially for small characteristic towns, which are more likely to be influenced by the external environment. At the same time, the generation of innovative ideas requires the exchange and collision of various ideas, which requires the characteristic town to have unobstructed, efficient and timely information access channels. Finally, policies are formulated to solve practical problems. Different regions have different development environments, and policies should also change according to time and place.

\subsection{Culture as the guide}

Where resource endowment, location conditions and industrial base are similar, some have grown characteristic towns, while others have not. An important factor behind this difference is cultural difference. The accumulation and evolution of culture is a long process with its own laws of development. Before the formation of the characteristic town, the main part of the culture in the region has already been formed, so its influence on the characteristic town is leading.
Profound cultural accumulation makes the town residents directly enjoy the spiritual, but also has a great attraction to people. With the inflow of talents, the industry will gather together, and the foundation of the development of characteristic towns will be gradually solid. Industrial agglomeration and development also need the town to have a deep cultural accumulation. Areas with profound cultural accumulation have higher quality of people, more diligent people and a stronger atmosphere of innovation, all of which provide a better environment for industrial development. Finally, culture is the spiritual soil where innovative activities take place. In such an atmosphere, innovative ideas are more likely to come into being, innovative results are more likely to be transformed, and emerging industries have greater opportunities for formation and development.

\subsection{Innovation as the driving force}

Innovation is the core driving force of economic growth and therefore the driving force of the formation and development of characteristic towns. Innovation promotes the all-round development of people by creating an innovative atmosphere, promotes the agglomeration of industries by giving play to market externalities and correlation effects, increases the vitality of culture by creating knowledge, collaboratively optimizes the development environment of enterprises by results transformation and innovation, and compensates for industrial failures by improving the policy system.

A good innovation atmosphere means that innovative talents can learn knowledge from the people around them, which is more conducive to the self-growth of talents. Once the innovation is applied in the market, it will be learned by other enterprises in the same industry. The new knowledge contained in it will gradually spread and gradually accumulate as a kind of public knowledge and eventually become a part of the culture. The spread of this new knowledge can benefit other regions at no cost. It is precisely the existence of spillover effect that may lead to the suppression of innovation enthusiasm, which requires the government to formulate innovation support policies to stimulate.

\subsection{Policy as the guarantee}

Characteristic town is a new thing, its whole development process needs the policy to guarantee. The path dependence effect of economic activities exists in space, that is, once economic activities gather in a place, they can "snowball" to strengthen their agglomeration advantages. Characteristic towns are at an absolute disadvantage in all aspects at the initial stage, so it is necessary to create an environment conducive to population and industrial agglomeration through policies.

Both the talent policy and the public service policy are closely related to the life of the townspeople and affect the 
attraction of the town to the talents. The initial stage of the industry in the characteristic town needs more policy support, otherwise it is difficult for the industry to gather and develop. Innovation is a high-risk activity. Under the same conditions, it is more advantageous to carry out innovation activities in big cities with strong conditions. That is to say, without any policy support, characteristic towns have no advantages in carrying out innovation activities, so policies are necessary to stimulate the innovation of characteristic towns.

\section{CONCLUSION}

Understanding the basic characteristics of characteristic towns is a prerequisite for ensuring scientific and rational policies. The six elements are the foundation of the formation and operation of the characteristic town, and the interrelation among them determines the characteristics and development state of the characteristic town. In the future, the construction of the characteristic town should strive to create a new home for the all-round development of people, a new highland for the gathering of characteristic industries, a new space for people to live, work and travel, a new name card for the display of regional culture, a new fertile land for the promotion of innovation and entrepreneurship, and a test field for the reform of the system and mechanism.

\section{ACKNOWLEDGMENT}

This work was supported by Horizontal Project of Shandong Youth University of Political Science: Research on the Development Model of Well-being Tourism Industry under the Background of Rural Revitalization Strategy.

\section{REFERENCES}

[1] Sheng Shihao, Zhang Weiming. Characteristic town: a form of industrial spatial organization [J]. Zhejiang social sciences, 2016, (3): 36-38 DOI: CNKI: SUN: ZJSH.0.2016-03-005

[2] Ma Bin. Characteristic town: the grand strategy of zhejiang's economic transformation and upgrading [J]. Zhejiang social sciences, 2016, (3): 39-42 DOI: CNKI: SUN: ZJSH.0.2016-03-006

[3] Liu Xibin. How to "push" the orderly construction of characteristic towns [J]. Zhejiang economy, 2015, (12): 4445 DOI: 10.3969/j.issn.1005-1635.2015.12.032

[4] Yao Shangjian. Integration of governance in urban-rural integration -- policy issues based on "characteristic towns" [J]. Social science research, 2017, 1:7-8 DOI : 10.3969/j.issn.1000-4769.2017.01.007

[5] Wang Xingbin. The soul of characteristic town is industry [J]. China real estate, 2017, 557 (20): 49-52 DOI : CNKI: SUN: GFCD.0.2017-20-024

[6] Cao Shuang, Luo Juan. Research status and prospect of China's characteristic town [J]. Reform and opening up, 2017 (11). DOI: 10.16653/j.cnki.32-1034/f.2017.011.007

[7] Zhang Yinyin, Ding yuan. Reference of foreign characteristic towns to the construction of characteristic towns in zhejiang [J]. Small town construction, 2016, 11 DOI: $10.3969 /$ j.issn.1002-8439.2016.11.008

[8] Zhu yingying. Path evolution, development dilemma and countermeasures of characteristic town construction [J]. Journal of jiaxing university, 2017, 029 (004): 30-39. DOI: $10.3969 /$ i.issn.1671-3079.2017.04.005 